\title{
Measurement equivalence of the SF-36 in the canadian multicentre osteoporosis study
}

\author{
Lisa M Lix ${ }^{1 *}$, Beliz Acan Osman ${ }^{2 \dagger}$, Jonathan D Adachi ${ }^{3+}$, Tanveer Towheed ${ }^{4 \dagger}$, Wilma Hopman ${ }^{4 \dagger}$, K Shawn Davison ${ }^{5 \dagger}$ \\ and William D Leslie ${ }^{6+}$
}

\begin{abstract}
Background: Studies that compare health-related quality of life (HRQOL) and other patient-reported outcomes in different populations rest on the assumption that the measure has equivalent psychometric properties across groups. This study examined the measurement equivalence (ME) of the 36-item Medical Outcomes Study Short Form Survey (SF-36), a widely-used measure of $\mathrm{HRQOL}$, by sex and race in a population-based Canadian sample.

Findings: SF-36 data were from the Canadian Multicentre Osteoporosis Study, a prospective cohort study that randomly sampled adult men and women from nine sites across Canada. Confirmatory factor analysis (CFA) techniques were used to test hypotheses about four forms of ME, which are based on equality of the factor loadings, variances, covariances, and intercepts. Analyses were conducted for Caucasian and non-Caucasian females $(n=6,539)$ and males $(n=2,884)$. CFA results revealed that a measurement model with physical and mental health factors provided a good fit to the data. All forms of ME were satisfied for the study groups.
\end{abstract}

Conclusions: The results suggest that sex and race do not influence the conceptualization of a general measure of $\mathrm{HRQOL}$ in the Canadian population.

Keywords: SF-36, Health-related quality of life, Psychometrics, Equivalence, Confirmatory factor analysis

\section{Findings}

The psychometric properties of health-related quality of life (HRQOL) measures and other patient-reported outcomes are an important consideration when undertaking studies in populations with diverse cultural or racial compositions [1]. The Medical Outcomes Study 36-item Short Form Survey (SF-36) is a well-known HRQOL measure used in many countries. While studies have been undertaken about its reliability and validity in different populations [2], its measurement equivalence (ME) properties have not been well examined. ME evaluations seek to answer the question: "Do individuals from different populations interpret a measure in a conceptually similar manner?" [3]. If ME is not tenable, then researchers cannot validly conclude that differences between groups correspond to true population differences because they will be confounded by measurement

\footnotetext{
* Correspondence: lisa.lix@usask.ca

+ Contributed equally

'School of Public Health, University of Saskatchewan, 107 Wiggins Road, Saskatoon, SK, Canada

Full list of author information is available at the end of the article
}

artifact. Measurement non-equivalence may exist, in part, because study participants do not interpret questions about their health using the same frame of reference $[4,5]$.

The purpose of this study is to investigate the ME of the SF-36 by sex and race. We focus on its properties in the Canadian population, where normative data for the SF-36 have now been published [6].

\section{Methods}

Study data were from the Canadian Multicentre Osteoporosis Study (CaMos), an ongoing prospective cohort study undertaken to provide national estimates of the prevalence and incidence of osteoporosis and osteoporosis-related fractures. The study population is composed of non-institutionalized men and women residing within a $50-\mathrm{km}$ radius of nine centers across Canada. These geographic areas encompass approximately 40 percent of the national population and include rural and urban residents. A random sample was taken from each site; details of the data collection 
methodology and participant characteristics have been reported previously $[6,7]$.

The sample consisted of all CaMos respondents for whom baseline data were obtained. Data collection occurred between January 1996 and September 1997 by means of an interviewer-administered questionnaire. Informed consent was obtained from participants and ethical approval was provided by the review boards of each participating center and the coordinating center in Montreal.

The SF-36 encompasses eight domains: physical functioning $(\mathrm{PF})$, role physical (RP), bodily pain (BP), general health $(\mathrm{GH})$, vitality $(\mathrm{VT})$, social functioning $(\mathrm{SF})$, role emotional (RE), and mental health (MH). Each domain is scored on a standardized scale with values ranging from 0 to 100 . Higher scores indicate better HRQOL [8]. In previous Canadian research, Cronbach's $\alpha$ ranged from 0.76 to 0.93 for the eight domains, with the lowest value for the SF domain [9]. Test-retest reliability has not been reported for the Canadian population, but in other populations a median reliability greater than 0.80 was reported for all but the SF domain, which had a median reliability of 0.76 [10].

Race, age in years, and sex were recorded during the interviews. For race, respondents were initially assigned to Caucasian, Asian, and Other categories. These categories were subsequently collapsed into Caucasian and non-Caucasian.

The data were described using frequencies and means. Hypotheses about ME were initially tested for the following pairs of study groups: (a) Caucasian and nonCaucasian females, (b) Caucasian and non-Caucasian males, (c) Caucasian males and females, and (d) nonCaucasian males and females. Subsequently, we tested ME hypotheses in age-matched groups, in which nonCaucasians were matched with Caucasians using age (in years) as the matching variable. The latter analyses were conducted to adjust for the potential confounding effects of age.

Four forms of ME were investigated using confirmatory factor analysis (CFA) [3,11,12]: configural, weak, strong, and complete. A series of two-group CFA models were fit to the data for each pair of study groups. Weak, strong, and complete invariance was tested in sequence by placing constraints on the parameters (i.e., factor loadings, intercepts, and error variances) of the configural invariance model $[3,11]$. Configural invariance, the simplest form of ME, is satisfied if a defined factor structure is a good fit to the data for both groups. It was evaluated using absolute and incremental goodness-of-fit statistics and published cut-off criteria [13-15]. The statistics included the model $\chi^{2}$, root mean square error of approximation (RMSEA) and its $90 \%$ confidence interval $(\mathrm{CI})$, root mean squared residual
(SRMR), comparative fit index (CFI) and non-normed fit index (NNFI). Model modification indices were calculated for the configural invariance model to guide decisions about its specification. These indices measure the predicted change in the $\chi^{2}$ statistic if a parameter is added or removed from the model and re-estimated.

A test of weak invariance assesses whether the factor loadings are the same for the groups. When weak invariance is satisfied, the latent variables are being measured in the same way for the groups. A test of strong invariance is used to assess whether the factor loadings and latent variable intercepts (i.e., means) are the same for the groups. If strong invariance does not hold then it is not valid to make group comparisons on the domain means. Complete invariance holds if the factor loadings, intercepts, and error variances are equivalent for the groups [11]. A LR statistic based on the difference in $\chi^{2}$ values for unconstrained and constrained models (i.e., $\Delta$ $\chi^{2}$ ), was used to test weak, strong, and complete invariance. The difference in CFI values for nested models (i. e., $\triangle \mathrm{CFI}$ ) was also used to assess invariance because the LR statistic is sensitive to sample size. An absolute value of $\triangle$ CFI less than or equal to 0.01 indicates the null hypothesis of invariance should not be rejected, while an absolute value greater than or equal to 0.02 indicates a likely difference in fit between constrained and unconstrained models [16]. $\triangle$ CFI was given more weight than the LR test when there was disagreement between the two statistics.

Robust maximum likelihood was used to estimate model parameters because the data exhibited a multivariate non-normal distribution [17]. Accordingly, Satorra-Bentler (SB)-scaled $\chi^{2}$ statistics, which correct for non-normality using RML were adopted [18]. Analyses were conducted using LISREL 8.80 [19].

\section{Results}

Data for 9,423 CaMos participants (Table 1) were included in the analysis. Two-thirds of participants were female. The majority (94.9\%) was Caucasian and this percentage was similar for males and females. Average scores for each of the SF-36 domains (Table 2) revealed that males tended to have higher HRQOL than females. For females, scores for Caucasians were often lower than those for non-Caucasians. For males, this was not always the case.

The initial configural invariance model (Figure 1) was fit to the data for each study group. This model was selected based on previous research that supports a twofactor model with four domains each measuring physical and mental health latent variables [10]. Based on the $\chi^{2}$ statistic, RMSEA, and SRMR (Table 3), this model did not provide a good fit to the data. Model modification indices suggested that substantial improvement in fit 
Table 1 Distribution of the CaMos cohort by sex, age, and race

\begin{tabular}{|c|c|c|c|c|c|c|c|c|c|c|c|c|}
\hline \multirow[t]{3}{*}{ Age (years) } & \multicolumn{6}{|c|}{ Female } & \multicolumn{6}{|l|}{ Male } \\
\hline & \multicolumn{2}{|c|}{ Caucasian } & \multicolumn{2}{|c|}{ Asian } & \multicolumn{2}{|c|}{ Other } & \multicolumn{2}{|c|}{ Caucasian } & \multicolumn{2}{|c|}{ Asian } & \multicolumn{2}{|c|}{ Other } \\
\hline & $n$ & $\%$ & $n$ & $\%$ & $n$ & $\%$ & $n$ & $\%$ & $n$ & $\%$ & $n$ & $\%$ \\
\hline $25-49$ & 902 & 14.1 & 30 & 22.1 & 41 & 29.3 & 639 & 23.8 & 28 & 26.9 & 30 & 30.9 \\
\hline 50-59 & 1,274 & 20.3 & 40 & 20.4 & 38 & 27.1 & 554 & 20.7 & 18 & 17.3 & 30 & 30.9 \\
\hline $60-69$ & 1,963 & 31.3 & 42 & 30.9 & 39 & 27.9 & 711 & 26.5 & 25 & 24.0 & 23 & 23.7 \\
\hline $70+$ & 2,124 & 33.9 & 24 & 17.7 & 22 & 15.7 & 779 & 29.0 & 33 & 31.7 & 14 & 14.4 \\
\hline Total & 6,263 & 100.0 & 136 & 100.0 & 140 & 100.0 & 2683 & 100.0 & 104 & 100.0 & 97 & 100.0 \\
\hline
\end{tabular}

could be obtained by including covariances among the residual errors of the SF-36 domains for RP and GH, VT and SF, and RP and RE. With these modifications (Table 3), all goodness-of-fit statistics indicated a wellfitting model.

The hypothesis of weak invariance was tested for this measurement model (Table 4). It was retained for all pairs of subgroups based on the $\Delta$ CFI, although the LR statistic was statistically significant for Caucasian and non-Caucasian females. The null hypothesis of strong

Table 2 Means and standard deviations (SDs) for the SF36 domains

\begin{tabular}{|c|c|c|c|}
\hline Domain & Race & Female & Male \\
\hline \multirow[t]{3}{*}{ Physical functioning } & Caucasian & 73.49 (25.32) & $81.33(22.27)$ \\
\hline & Non-Caucasian & 79.69 (21.18) & $82.17(21.57)$ \\
\hline & All Groups & 73.75 (25.19) & $81.39(22.22)$ \\
\hline \multirow[t]{3}{*}{ Role physical } & Caucasian & $74.08(38.16)$ & $81.50(33.28)$ \\
\hline & Non-Caucasian & $79.62(35.85)$ & $81.84(33.72)$ \\
\hline & All Groups & 74.31 (38.08) & $81.53(33.31)$ \\
\hline \multirow[t]{3}{*}{ Bodily pain } & Caucasian & $70.82(24.61)$ & 76.79 (22.46) \\
\hline & Non-Caucasian & $76.00(24.18)$ & $79.41(24.25)$ \\
\hline & All Groups & $71.04(24.61)$ & $76.97(22.59)$ \\
\hline \multirow[t]{3}{*}{ General health } & Caucasian & $73.92(19.04)$ & 74.69 (17.90) \\
\hline & Non-Caucasian & $70.95(19.37)$ & $73.37(19.19)$ \\
\hline & All Groups & $73.80(19.06)$ & 74.59 (17.99) \\
\hline \multirow[t]{3}{*}{ Vitality } & Caucasian & $62.63(19.87)$ & $67.80(17.83)$ \\
\hline & Non-Caucasian & $64.74(19.42)$ & $68.93(17.23)$ \\
\hline & All Groups & $62.71(19.85)$ & $67.88(17.78)$ \\
\hline \multirow[t]{3}{*}{ Social functioning } & Caucasian & $85.49(21.37)$ & $89.03(18.71)$ \\
\hline & Non-Caucasian & $84.60(21.42)$ & $83.21(22.21)$ \\
\hline & All Groups & $85.46(21.37)$ & $88.62(19.03)$ \\
\hline \multirow[t]{3}{*}{ Role emotional } & Caucasian & $83.56(32.07)$ & $87.90(27.82)$ \\
\hline & Non-Caucasian & $82.61(34.75)$ & $82.26(33.83)$ \\
\hline & All Groups & $83.52(32.19)$ & $87.50(28.31)$ \\
\hline \multirow[t]{3}{*}{ Mental health } & Caucasian & 77.78 (15.56) & 81.09 (13.89) \\
\hline & Non-Caucasian & $78.23(16.91)$ & $80.89(14.89)$ \\
\hline & All Groups & $77.80(15.62)$ & $81.08(13.95)$ \\
\hline
\end{tabular}

The non-Caucasian group includes Asian and Other groups invariance was retained for all pairs of study groups based on the $\triangle$ CFI statistics. Finally, the hypothesis of complete invariance was retained for all pairs of study groups according to $\Delta$ CFI statistics. Subsequent analyses for the age-matched study groups resulted in the same conclusions about all ME hypotheses.

\section{Discussion}

This study investigated the psychometric equivalence of the SF-36 by sex and race in a population-based cohort that represents a large proportion of the Canadian population. These stratification variables were selected because previous research indicates they are associated with differences in the conceptualization of HRQOL and other patient-reported outcomes [2]. All forms of ME were supported in each of the four analyses.

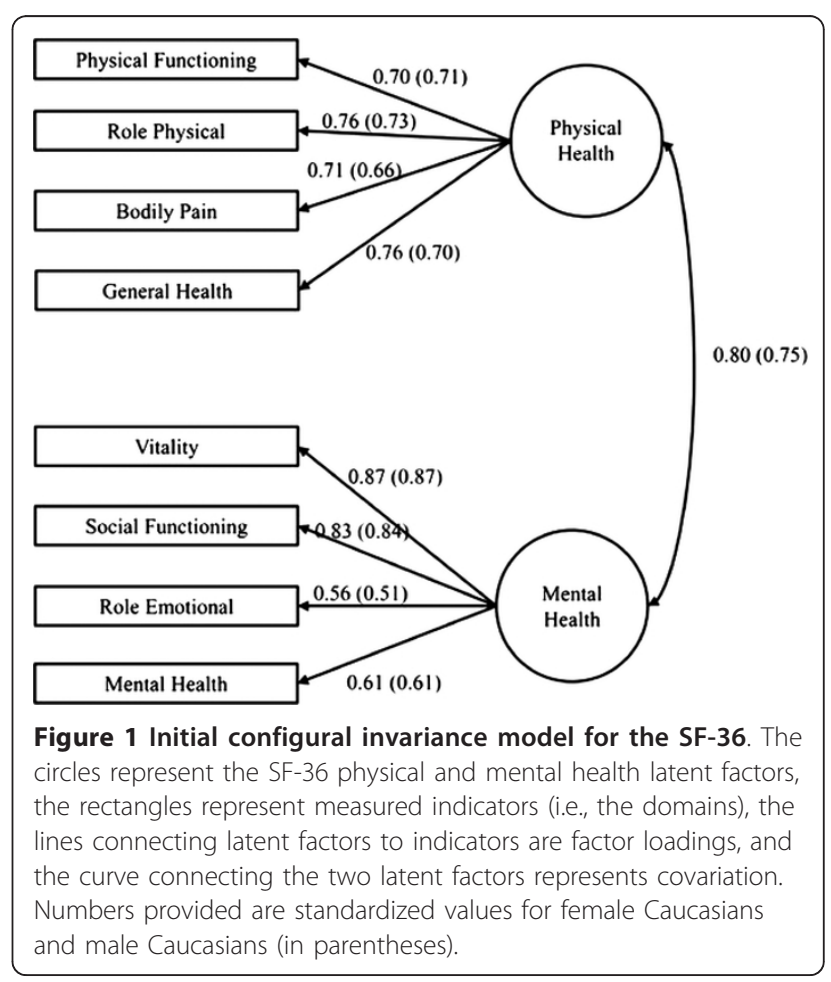


Table 3 Fit statistics for initial and modified configural invariance model for the SF-36

\begin{tabular}{|c|c|c|c|c|c|c|}
\hline $\begin{array}{l}\text { Study } \\
\text { group }\end{array}$ & Model & SB $\chi^{2}$ & $\begin{array}{l}\text { RMSEA }(90 \% \\
\text { Cl) }\end{array}$ & SRMR & CFI & $\mathrm{NNFI}$ \\
\hline \multirow{2}{*}{$\begin{array}{l}\text { Female, } \\
\text { Caucasian }\end{array}$} & Initial & $1584.95^{*}$ & $0.12(0.11,0.12)$ & 0.06 & 0.96 & 0.94 \\
\hline & Modified & $976.36^{*}$ & $0.10(0.09,0.10)$ & 0.05 & 0.97 & 0.96 \\
\hline \multirow{2}{*}{$\begin{array}{l}\text { Male, } \\
\text { Caucasian }\end{array}$} & Initial & $718.18^{*}$ & $0.12(0.11,0.13)$ & 0.07 & 0.95 & 0.92 \\
\hline & Modified & $404.36^{*}$ & $0.10(0.09,0.10)$ & 0.05 & 0.97 & 0.95 \\
\hline $\begin{array}{l}\text { Female, } \\
\text { non- }\end{array}$ & Initial & $81.58^{*}$ & $0.11(0.09,0.14)$ & 0.06 & 0.96 & 0.95 \\
\hline
\end{tabular}

Caucasian

\begin{tabular}{|c|c|c|c|c|c|c|}
\hline & Modified & $45.64^{*}$ & $0.08(0.06,0.11)$ & 0.04 & 0.98 & 0.97 \\
\hline Male, & Initial & $68.23^{*}$ & $0.11(0.09,0.14)$ & 0.07 & 0.95 & 0.93 \\
\hline
\end{tabular}

non-

Caucasian

$$
\begin{array}{lllll}
\hline \text { Modified } 33.35^{*} & 0.07(0.04,0.11) & 0.05 & 0.98 & 0.97
\end{array}
$$

$\mathrm{SB}=$ Satorra-Bentler: RMSEA = root mean square error of approximate $\mathrm{Cl}=$ confidence interval; $\mathrm{CFI}=$ comparative fit index; NNFI = non-normed fit index; Initial model, which is defined in Figure 1, has 19 degrees of freedom and the modified model has 16 degrees of freedom; ${ }^{*}$ denotes a SB $\chi^{2}$ statistic that is statistically significant at $\alpha=.05$

This study adopted stringent criteria for establishing ME of the SF-36. While configural and weak invariance are usually tested, Gregorich [20] notes that strong and complete invariance are less frequently considered,

Table 4 Tests of measurement equivalence for the SF-36

\begin{tabular}{lllllll}
\hline Equivalence Hypothesis & SB $\chi^{2}$ & $d f$ & $\Delta$ SB $\chi^{2}$ & $\Delta d f$ & CFI & $\Delta$ CFI \\
\hline Configural & Caucasian and non-Caucasian females \\
\hline Weak & 1067.88 & 32 & - & - & 0.97 & - \\
\hline Strong & 1077.48 & 38 & $22.58^{*}$ & 6 & 0.97 & 0.00 \\
\hline Complete & 1212.23 & 46 & $82.05^{*}$ & 8 & 0.97 & 0.00 \\
\hline Configural & 1174.84 & 60 & 21.67 & 14 & 0.97 & 0.00 \\
\hline Weak & Caucasian and non-Caucasian males & \\
\hline Strong & 486.87 & 32 & - & - & 0.97 & - \\
\hline Complete & 500.21 & 38 & 10.80 & 6 & 0.97 & 0.00 \\
\hline Configural & 561.17 & 46 & $41.58^{*}$ & 8 & 0.96 & 0.01 \\
\hline Weak & 501.75 & 66 & $28.40^{*}$ & 14 & 0.97 & 0.01 \\
\hline Strong & Caucasian females and males & & \\
\hline Complete & 1356.11 & 32 & - & - & 0.97 & - \\
\hline Configural & 1355.13 & 38 & 6.74 & 6 & 0.97 & 0.00 \\
\hline Weak & 1693.35 & 46 & $364.97^{*}$ & 8 & 0.97 & 0.00 \\
\hline Strong & 1966.86 & 60 & $242.87^{*}$ & 14 & 0.96 & 0.01 \\
\hline Complete & non-Caucasian females and males & \\
\hline SB Satora-Benter & 79.49 & 32 & - & - & 0.98 & - \\
\hline & 83.33 & 38 & 4.69 & 6 & 0.98 & 0.00 \\
\hline 99.81 & 46 & $16.23^{*}$ & 8 & 0.98 & 0.00 \\
\hline 106.53 & 60 & 10.84 & 14 & 0.98 & 0.00 \\
\hline
\end{tabular}

SB = Satorra-Bentler; ${ }^{*}$ denotes a SB $\chi^{2}$ statistic that is statistically significant at $\alpha=.05$ despite the fact that equality of factor loadings, intercepts, and error variances is critical to making valid group comparisons [21]. Vandenberg and Lance [11] found that weak invariance was investigated in $99 \%$ of studies but strong invariance was tested in only about $12 \%$ of studies. However, this research also has some limitations. ME was investigated for a single measure; other measures of HRQOL might not be psychometrically equivalent. Other stratification variables may have been considered in the ME models, such as education [22]. However, further stratification of the data would have resulted in sample sizes too small to result in valid tests of the study hypotheses. The initial factor structure selected for the SF-36 domains did not provide a good fit to the data. It was modified to allow for correlation among the residual errors of selected domains. While this model was consistent with previous research [23], it may not be consistent with the measurement model adopted in other studies. Finally, only a single statistical method, CFA, was used to test ME. Item response theory has also been proposed for evaluating equivalence and these approaches may not concur [24].

Establishing ME across populations is a prerequisite for conducting valid tests of hypotheses about equality of group means or variances. The findings of this study suggest that sex and race do not influence the conceptualization of a general measure of HRQOL in the Canadian population.

\section{Abbreviations}

BP: Bodily pain; CaMos: Canadian Multicentre Osteoporosis Study; CFA: Confirmatory factor analysis; CFI: Comparative fit index; Cl: Confidence interval; GH: General health; HRQOL: Health-related quality of life; ME: Measurement equivalence; MH: Mental health; NNFI: Non-normed fit index; PF: Physical functioning; RE: Role emotional; RMSEA: Root mean square error of approximation; SRMR: Root mean squared residual; RP: Role physical; SB: Satorra-Bentler; SF: Social functioning; SF-36: 36-item Medical Outcomes Study Short Form Survey; VT: Vitality.

\section{Acknowledgements}

The first author is supported by a Canadian Institutes of Health Research New Investigator Award and the University of Saskatchewan Centennial Chair. We thank all those participants in CaMos whose careful responses and attendance made this analysis possible. We thank the CaMos Research Group for access to the data to complete this study.

CaMos Research Group

David Goltzman (co-principal investigator, McGill University), Nancy Kreiger (co-principal investigator, Toronto), Alan Tenenhouse (principal investigator emeritus, Toronto),

CaMos Coordinating Centre, McGill University, Montreal, Quebec: Suzette Poliquin (national coordinator), Suzanne Godmaire (research assistant), Silvia Dumont (administrative assistant), Claudie Berger (study statistician), Lisa Langsetmo (Fellow), Wei Zhou (statistician)

Memorial University, St. John's Newfoundland: Carol Joyce (director), Christopher Kovacs (co-director), Emma Sheppard (coordinator). Dalhousie University, Halifax, Nova Scotia: Susan Kirkland, Stephanie Kaiser (co-directors), Barbara Stanfield (coordinator).

Laval University, Quebec City, Quebec: Jacques P. Brown (director), Louis Bessette (co-director), Marc Gendreau (coordinator).

Queen's University, Kingston, Ontario: Tassos Anastassiades (director), Tanveer Towheed (co-director), Barbara Matthews (coordinator). 
University of Toronto, Toronto, Ontario: Bob Josse (director), Sophie Jamal (co-director), Tim Murray (past director), Barbara Gardner-Bray (coordinator) McMaster University, Hamilton, Ontario: Jonathan D. Adachi (director), Alexandra Papaioannou (co-director), Laura Pickard (coordinator). University of Saskatchewan, Saskatoon, Saskatchewan: Wojciech P. Olszynski (director), K. Shawn Davison (co-director), Jola Thingvold (coordinator). University of Calgary, Calgary, Alberta: David A. Hanley (director), Jane Allan (coordinator).

University British Columbia, Vancouver, British Columbia: Jerilynn C. Prior (director), Millan Patel (co-director), Yvette Vigna (coordinator), Brian Lentle (radiologist).

\section{Author details}

'School of Public Health, University of Saskatchewan, 107 Wiggins Road, Saskatoon, SK, Canada. ${ }^{2}$ Health Quality Council, 111 Research Drive, Saskatoon, SK, Canada. ${ }^{3}$ Faculty of Health Sciences, McMaster University, 1280 Main St. W, Hamilton, ON, Canada. ${ }^{4}$ Department of Community Health and Epidemiology, Carruthers Hall, Queen's University, Kingston, ON, Canada. ${ }^{5}$ College of Kinesiology, University of Saskatchewan, 87 Campus Drive, Saskatoon, Canada. ${ }^{6}$ Department of Internal Medicine, University of Manitoba, St. Boniface General Hospital, 409 Tache Avenue, Winnipeg, MB, Canada.

\section{Authors' contributions}

LML planned the study and analyses and drafted the manuscript. BAO conducted the analyses and drafted the manuscript. JA, $\Pi$, SD, WH, and WDL participated in planning the study and facilitating data access. All authors read and approved the final manuscript.

\section{Competing interests}

The authors declare that they have no competing interests

Received: 11 April 2011 Accepted: 13 March 2012

Published: 13 March 2012

\section{References}

1. McHorney CA, Fleishman JA: Assessing and understanding measurement equivalence in health outcome measures. Issues for further quantitative and qualitative inquiry. Med Care 2006, 44:S205-S210.

2. Keller SD, Ware JE Jr, Bentler PM, Aaronson NK, Alonso J, Apolone G, Bjorner JB, Brazier J, Bullinger M, Kaasa S, et al: Use of structural equation modeling to test the construct validity of the SF-36 Health Survey in ten countries: results from the IQOLA Project. International Quality of Life Assessment. J Clin Epidemiol 1998, 51:1179-1188.

3. Meredith W, Teresi JA: An essay on measurement and factorial invariance. Med Care 2006, 44:S69-S77.

4. Lubetkin El, Jia H, Franks P, Gold MR: Relationship among sociodemographic factors, clinical conditions, and health-related quality of life: examining the EQ-5D in the U.S. general population. Qual Life Res 2005, 14:2187-2196.

5. Avis NE, Assmann SF, Kravitz HM, Ganz PA, Ory M: Quality of life in diverse groups of midlife women: Assessing the influence of menopause, health status and psychosocial and demographic factors. Qual Life Res 2004, 13:933-946.

6. Hopman WM, Towheed T, Anastassiades T, Tenenhouse A, Poliquin S, Berger C, Joseph L, Brown JP, Murray TM, Adachi JD, et al: Canadian normative data for the SF-36 health survey. Can Med Assoc J 2000, 163:265-271.

7. Adachi JD, loannidis G, Berger C, Joseph L, Papaioannou A, Pickard L, Papadimitropoulos EA, Hopman W, Poliquin S, Prior JC, et al: The influence of osteoporotic fractures on health-related quality of life in communitydwelling men and women across Canada. Osteoporos Int 2001, 12:903-908.

8. Ahmed S, Mayo NE, Corbiere M, Wood-Dauphinee S, Hanley J, Cohen R: Change in quality of life of people with stroke over time: true change or response shift? Qual Life Res 2005, 14:611-627.

9. Wood-Dauphinee S, Gauthier L, Gandek B, Magnan L, Pierre U: Readying a US measure of health status, the SF-36, for use in Canada. Clin Invest Med 1997, 20:224-238.
10. Ware JE Jr, Snow KK, Kosinski M, Gandek B: SF-36 health survey: manual and interpretation guide Boston, MA: The Health Institute, New England Medical Center; 1993.

11. Vandenberg RJ, Lance CE: A review and synthesis of the measurement invariance literature: suggestions, practices, and recommendations for organizational research. Organ Res Methods 2000, 3:4-70.

12. Horn JL, McArdle JJ: A Practical and Theoretical Guide to Measurement Invariance in Aging Research. Exp Aging Res 1992, 18:117-144.

13. Browne MW, Cudeck R: Alternative ways of assessing model fit. In Testing structural equation models. Edited by: Bollen K, Long JS. Newbury Park: Sage Publications; 1993:136-162.

14. Hu LT, Bentler PM: Cutoff criteria for fit indices in covariance structure analysis: conventional criteria versus new alternatives. Struct Equ Modeling 1999, 6:1-55.

15. Bentler PM: Comparative Fit Indexes in Structural Models. Psychol Bull 1990, 107:238-246

16. Cheung GW, Rensvold RB: Evaluating goodness-of-fit indexes for testing measurement invariance. Struct Equ Modeling 2002, 9:233-255.

17. Mardia KV: Applications of some measures of multivariate skewness and kurtosis in testing normality and robustness studies. Sankhya Ser B 1974, 36:115-128.

18. Satorra A, Bentler PM: A scaled difference chi-square test statistic for moment structure analysis. Psychometrika 2001, 66:507-514.

19. Joreskog KG, Sorbom D: Lisrel 8: user's reference guide Chicago, IL: Scientific Software International; 1996.

20. Gregorich SE: Do self-report instruments allow meaningful comparisons across diverse population groups? Testing measurement invariance using the confirmatory factor analysis framework. Med Care 2006, 44: S78-S94.

21. Wu AD, Li Z, Zumbo BD: Decoding the meaning of factorial invariance and updating the practice of multi-group confirmatory factor analysis: a demonstration with TIMSS data. PARE 2007, 12(3)[http://pareonline.net/ getvn.asp? $=12 \& n=3]$.

22. Regidor E, Barrio B, de la Fuente L, Domingo A, Rodiguez C, Alonso J: Association between educational level and health related quality of life in Spanish adults. J Epidemiol Community Health 1999, 53:75-82.

23. Lix LM, Metge C, Leslie WD: Measurement equivalence of osteoporosisspecific and general quality-of-life instruments in Aboriginal and nonAboriginal women. Qual Life Res 2009, 18:619-627.

24. Teresi JA, Ocepek-Welikson K, Kleinman M, Cook KF, Crane PK, Gibbons LE, Morales LS, Orlando-Edelen M, Cella D: Evaluating measurement equivalence using the item response theory log-likelihood ratio (IRTLR) method to assess differential item functioning (DIF): applications (with illustrations) to measures of physical functioning ability and general distress. Qual Life Res 2007, 16:43-68.

doi:10.1186/1477-7525-10-29

Cite this article as: Lix et al:: Measurement equivalence of the SF-36 in the canadian multicentre osteoporosis study. Health and Quality of Life Outcomes 2012 10:29.

\section{Submit your next manuscript to BioMed Central and take full advantage of:}

- Convenient online submission

- Thorough peer review

- No space constraints or color figure charges

- Immediate publication on acceptance

- Inclusion in PubMed, CAS, Scopus and Google Scholar

- Research which is freely available for redistribution

Submit your manuscript at www.biomedcentral.com/submit
C Biomed Central 